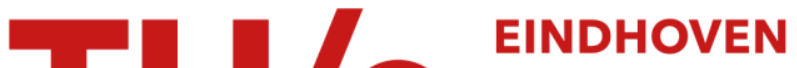 \\ UNIVERSITY OF \\ TECHNOLOGY
}

\section{Strain engineering in Ge/GeSn core/shell nanowires}

\section{Citation for published version (APA):}

Assali, S., Albani, M., Bergamaschini, R., Verheijen, M. A., Li, A., Kölling, S., Gagliano, L., Bakkers, E. P. A. M., \& Miglio, L. (2019). Strain engineering in Ge/GeSn core/shell nanowires. Applied Physics Letters, 115(11),

[113102]. https://doi.org/10.1063/1.5111872

DOI:

10.1063/1.5111872

Document status and date:

Published: 09/09/2019

\section{Document Version:}

Publisher's PDF, also known as Version of Record (includes final page, issue and volume numbers)

\section{Please check the document version of this publication:}

- A submitted manuscript is the version of the article upon submission and before peer-review. There can be important differences between the submitted version and the official published version of record. People interested in the research are advised to contact the author for the final version of the publication, or visit the $\mathrm{DOI}$ to the publisher's website.

- The final author version and the galley proof are versions of the publication after peer review.

- The final published version features the final layout of the paper including the volume, issue and page numbers.

Link to publication

\section{General rights}

Copyright and moral rights for the publications made accessible in the public portal are retained by the authors and/or other copyright owners and it is a condition of accessing publications that users recognise and abide by the legal requirements associated with these rights.

- Users may download and print one copy of any publication from the public portal for the purpose of private study or research.

- You may not further distribute the material or use it for any profit-making activity or commercial gain

- You may freely distribute the URL identifying the publication in the public portal.

If the publication is distributed under the terms of Article 25fa of the Dutch Copyright Act, indicated by the "Taverne" license above, please follow below link for the End User Agreement:

www.tue.nl/taverne

Take down policy

If you believe that this document breaches copyright please contact us at:

openaccess@tue.nl

providing details and we will investigate your claim. 


\section{Strain engineering in Ge/GeSn core/shell nanowires $\odot$}

Cite as: Appl. Phys. Lett. 115, 113102 (2019); https://doi.org/10.1063/1.5111872

Submitted: 30 May 2019 . Accepted: 04 August 2019 . Published Online: 09 September 2019

S. Assali (D), M. Albani (D), R. Bergamaschini (D), M. A. Verheijen (D), A. Li, S. Kölling (D), L. Gagliano (D), E. P. A. M. Bakkers (D), and L. Miglio (iD)

\section{COLLECTIONS}

This paper was selected as Featured
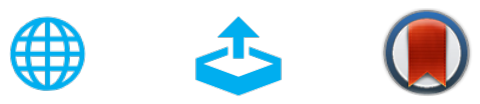

View Online

Export Citation

\section{ARTICLES YOU MAY BE INTERESTED IN}

Computer-automated tuning procedures for semiconductor quantum dot arrays

Applied Physics Letters 115, 113501 (2019); https://doi.org/10.1063/1.5121444

Enhanced superconductivity in $\mathrm{Bi}_{2} \mathrm{Se}_{3} / \mathrm{Nb}$ heterostructures

Applied Physics Letters 115, 113101 (2019); https://doi.org/10.1063/1.5109455

Honeycomb-serpentine silicon platform for reconfigurable electronics

Applied Physics Letters 115, 112105 (2019); https://doi.org/10.1063/1.5111018

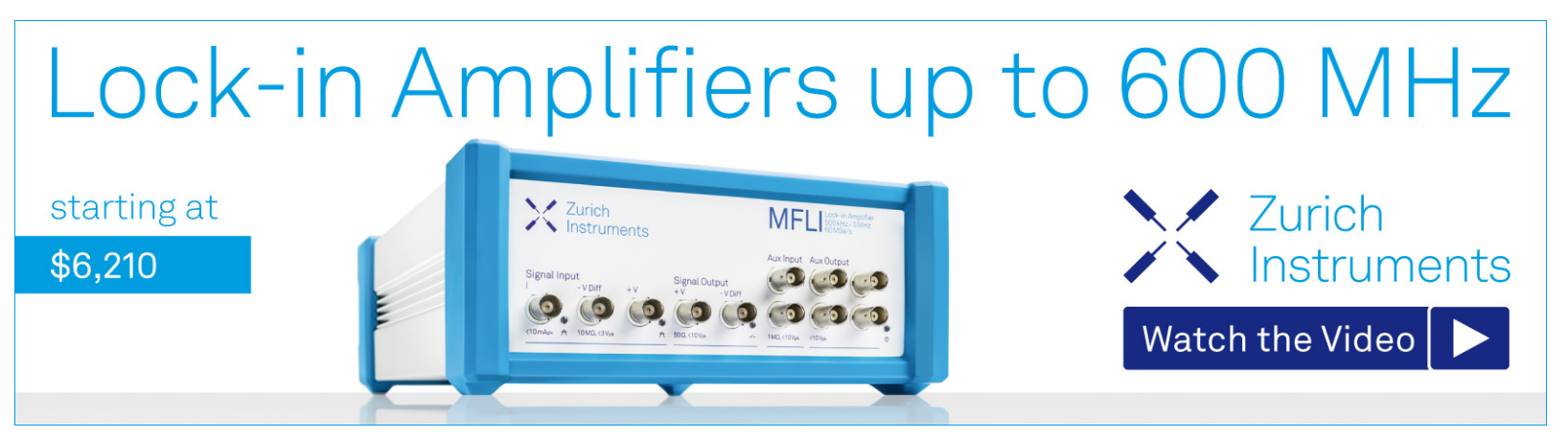




\title{
Strain engineering in Ge/GeSn core/shell nanowires
}

\author{
Cite as: Appl. Phys. Lett. 115, 113102 (2019); doi: 10.1063/1.5111872 \\ Submitted: 30 May 2019 . Accepted: 4 August 2019 . \\ Published Online: 9 September 2019
}

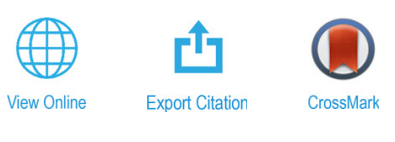

S. Assali, ${ }^{1,2, a), b)}$ (D M. Albani, ${ }^{3, a), b)}$ (D) R. Bergamaschini, ${ }^{3}$ (D) M. A. Verheijen, ${ }^{1,4}$ (D) A. Li, ${ }^{1,5,6}$ S. Kölling, ${ }^{1}$ (D) L. Gagliano,

E. P. A. M. Bakkers, ${ }^{1,6}$ (D) and L. Miglio ${ }^{3}$

\author{
AFFILIATIONS \\ 'Department of Applied Physics, Eindhoven University of Technology, 5600 MB Eindhoven, The Netherlands \\ ${ }^{2}$ Department of Engineering Physics, École Polytechnique de Montréal, C. P. 6079, Succ. Centre-Ville, Montréal, Québec H3C 3A7, \\ Canada \\ ${ }^{3}$ L-NESS and Department of Materials Science, University of Milano Bicocca, 20125, Milano, Italy \\ ${ }^{4}$ Eurofins Materials Science BV, High Tech Campus 11, 5656AE Eindhoven, The Netherlands \\ ${ }^{5}$ Beijing University of Technology, Pingleyuan 100, 100124, People's Republic of China \\ ${ }^{6}$ Kavli Institute of Nanoscience, Delft University of Technology, 2600 GA Delft, The Netherlands \\ a) Contributions: S. Assali and M. Albani contributed equally to this work. \\ b) Authors to whom correspondence should be addressed: simone.assali@polymtl.ca and marco.albani@unimib.it
}

\begin{abstract}
Strain engineering in Sn-rich group IV semiconductors is a key enabling factor to exploit the direct bandgap at mid-infrared wavelengths. Here, we investigate the effect of strain on the growth of GeSn alloys in a Ge/GeSn core/shell nanowire geometry by controlling the Ge core diameter and correlating the results with theoretical strain calculations. Incorporation of the Sn content in the 10-20 at. \% range is achieved with Ge core diameters ranging from $50 \mathrm{~nm}$ to $100 \mathrm{~nm}$. While the smaller cores lead to the formation of a regular and homogeneous GeSn shell, larger cores lead to the formation of multifaceted sidewalls and broadened segregation domains, inducing the nucleation of defects. This behavior is rationalized in terms of the different residual strain, as obtained by realistic finite element method simulations. The extended analysis of the strain relaxation as a function of core and shell sizes, in comparison with the conventional planar geometry, provides a deeper understanding of the role of strain in the epitaxy of metastable GeSn semiconductors.
\end{abstract}

Published under license by AIP Publishing. https://doi.org/10.1063/1.5111872

Strained semiconductor heterostructures provide a rich playground for investigating the epitaxy of lattice-mismatched materials. ${ }^{1}$ In the last few decades, SiGe alloys grown with a graded composition on $\mathrm{Si}$ were extensively studied to relieve strain by nucleating misfit dislocations in the buffer layers. ${ }^{2-4}$ Recently, direct bandgap and metastable GeSn alloys gained tremendous interest as a platform for Si-compatible photonics operating at mid-infrared wavelengths. ${ }^{5-9}$ In unstrained GeSn, the direct bandgap is achieved at Sn contents higher than 10 at. $\%$ and hence well above the $\sim 1$ at. \% equilibrium solubility of $\mathrm{Sn}$ in Ge. The incorporation of $\mathrm{Sn}$ is highly sensitive to the "in-plane" strain that the GeSn layer experiences during growth. ${ }^{10,11}$ Due to the large lattice mismatch between $\alpha$-Sn and Si $(\sim 20 \%)$, the growth of GeSn layers has been developed on high-quality Ge-virtual substrates (Ge-VS) on $\mathrm{Si}^{12,13}$ Partial strain relaxation can induce compositional grading in $\mathrm{GeSn},{ }^{8,14-16}$ eventually leading to segregation and precipitation of $\mathrm{Sn}$, compromising material quality. ${ }^{17-19}$ In $\mathrm{GeSn}$ layers grown on Ge-VS, the compressive strain is reduced in a multilayer buffered heterostructure grown with different $\mathrm{Sn}$ contents by controlling the growth temperature ${ }^{20,21}$ and precursor flows. ${ }^{22}$ The high amount of strain induces nucleation of dislocations in the low (7-11 at. \%) Sn content buffer layers, ${ }^{11,23}$ and the resulting uniform (plastic) strain relaxation enhances the $\mathrm{Sn}$ incorporation above 16 at. \% in the GeSn layers grown on top. ${ }^{8,11,14,19}$ One-dimensional nanowires (NWs) provide additional degrees of freedom in tuning the effect of strain in the growth of lattice-mismatch heterostructures ${ }^{24,25}$ when using a core/ shell NW geometry. ${ }^{26}$ The shell displays an increasing strain relaxation with the thickness provided by the free surfaces at the sidewalls, while the elastic compliance of the NW core allows for enhanced strain relaxation in the shell, accommodating the lattice mismatch of the system and avoiding bending. ${ }^{26,27}$ Recent studies on Ge/GeSn core/shell $\mathrm{NWs}^{15,16,28,29}$ are mainly focused on small Ge core-sizes, where a low amount of residual strain is induced in the GeSn shell. 
In this letter, we show how strain can be engineered by tuning the core and shell sizes and we explore high strain conditions focusing on large cores and high Sn contents. To this purpose, core diameters ranging from $50 \mathrm{~nm}$ to $100 \mathrm{~nm}$ are considered for the growth of the GeSn shell, and the samples are analyzed using transmission electron microscopy (TEM) to assess the crystal quality and the Sn incorporation. Realistic Finite Element Method (FEM) simulations are then performed to characterize the strain distribution in the grown samples and to correlate strain partitioning with NW geometry.

The vapor-liquid-solid (VLS) growth of Au-catalyzed arrays of $\mathrm{Ge} / \mathrm{GeSn}$ core/shell NWs is performed in a chemical vapor deposition (CVD) reactor using germane $\left(\mathrm{GeH}_{4}\right)$, tin-tetrachloride $\left(\mathrm{SnCl}_{4}\right)$, and hydrogen chloride $(\mathrm{HCl})$ as precursors (supplementary material $\mathrm{S} 1) .{ }^{15}$ The two-temperature step growth is held at $320^{\circ} \mathrm{C}$ and $300{ }^{\circ} \mathrm{C}$ for the Ge core and GeSn shell growth, respectively. Three different NW arrays with Ge core diameters of $50 \mathrm{~nm}, 65 \mathrm{~nm}$, and $100 \mathrm{~nm}$ were fabricated by controlling the Au layer thickness during nanoimprint lithography.

The scanning electron microscopy (SEM) image in Fig. 1(a) shows an array of $\mathrm{Ge} / \mathrm{Ge}_{0.895} \mathrm{Sn}_{0.105}$ core/shell NWs grown using a $50 \mathrm{~nm}$ core. Tapered top section and flat $\{112\}$ sidewalls are obtained, as previously discussed in Refs. 15 and 16. An important feature distinguishable in the bottom section of the NWs is a more complex faceting of the shell morphology, which was reported to be more evident for a higher $\mathrm{Sn}$ content $\mathrm{Ge}_{0.87} \mathrm{Sn}_{0.13}$ shell grown at a lower $\mathrm{GeH}_{4} /$ $\mathrm{SnCl}_{4}$ precursor ratio. ${ }^{15}$ The extension and morphology of the multifaceted bottom section are strongly influenced by the diameter of the Ge core, either defined by the size of the Au droplet, or resulting from the small tapering at the NW base. When the Ge core diameter is increased from $50 \mathrm{~nm}$ to $65 \mathrm{~nm}$, the length of the multifaceted bottom section extends to more than half of the NW length [Fig. 1(b)]. With a further increase in the Ge core diameter to $100 \mathrm{~nm}$, the shell becomes multifaceted [Fig. 1(c)] and its thickness decreases from $\sim 110 \mathrm{~nm}^{15,16}$ to $\sim 60 \mathrm{~nm}$. We note that the volume of the GeSn shell grown around the $100 \mathrm{~nm}$ Ge core is less than one half as compared to when using $50 \mathrm{~nm}$ cores. In addition, a small degree of tapering is always observed in the Ge core NW arrays, independently of the diameter (supplementary material S2). Therefore, the reduction in the shell thickness and volume with the development of a multifaceted sidewall is associated with the increase in the Ge core diameter. This suggests strain-driven growth kinetics during GeSn shell growth, which is a similar situation to what is observed in the growth of $\mathrm{GeSn}$ in a planar geometry. ${ }^{8,10,11}$ Furthermore, the $\mathrm{HCl}$ supply during the (a)

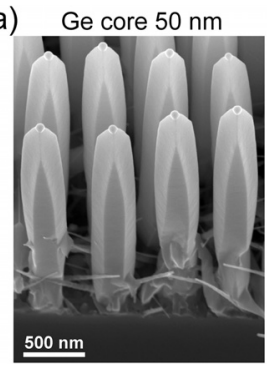

(b) Ge core $65 \mathrm{~nm}$

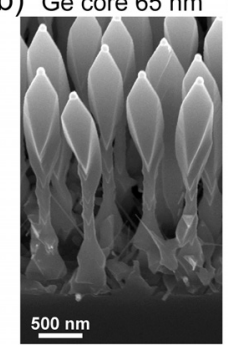

(c) Ge core $100 \mathrm{~nm}$

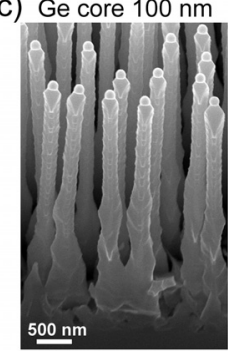

FIG. 1. (a)-(c) SEM images of the Ge/GeSn core/shell NW arrays (tilting angle $30^{\circ}$ ) grown using Ge core diameters of $50 \mathrm{~nm}(\mathrm{a}), 65 \mathrm{~nm}(\mathrm{~b})$, and $100 \mathrm{~nm}(\mathrm{c})$.
GeSn shell growth does not contribute to the change in the morphology in the bottom section of the NWs (supplementary material S3).

A detailed insight into the irregular morphology of the GeSn shell grown using $100 \mathrm{~nm}$ Ge cores is obtained using transmission electron microscopy (TEM). The GeSn shell is visible in the energy-dispersive $\mathrm{X}$-ray (EDX) compositional map acquired in scanning-TEM (STEM) mode in Fig. 2(a). No axial growth of a GeSn segment is observed, ${ }^{15}$ while a GeSn shell with a variable thickness and a multifaceted sidewall is visible in the TEM images in Figs. 2(b)-2(d). This faceting cannot be related to the core morphology, as the $100 \mathrm{~nm}$ Ge-core NWs have flat sidewalls, similar to the $50 \mathrm{~nm}$ cores (supplementary material S1). Moreover, the sidewall faceting does not correlate with the StranskiKrastanov (SK) instability that is observed in $\mathrm{Si} / \mathrm{Ge}$ core/shell NWs. ${ }^{30,31}$ The low growth temperature $\left(320^{\circ} \mathrm{C}\right)$ and the low(compressive) strain below $1 \%$ (Fig. 4 ) are not sufficient to trigger the SK instability. Thus, the change in shell morphology between the flat sidewall observed for $50 \mathrm{~nm}$ cores $^{15,16}$ and the multifaceted sidewall with $100 \mathrm{~nm}$ cores most likely relates to the larger amount of strain in the shell, as we will quantify in the following. Higher strain beyond a critical value leads to plastic relaxation, with the nucleation of defects in the core/shell NW heterostructure. Few defects are indeed visible in the core/shell NW in Figs. 2(b)-2(d), as indicated by the red arrows. Due to the large sample thickness, a precise identification of the type of defects in the shell, such as partial dislocations, is not possible. It is important to compare this situation with the NWs grown using a $50 \mathrm{~nm}$ Ge core, where no defect lines were identified in the $\sim 120 \mathrm{~nm}$ thick GeSn shell. ${ }^{15}$ In the growth of the GeSn shell around $100 \mathrm{~nm} \mathrm{Ge}$ cores, multiple defects can be identified in the GeSn shell with a thickness of only $\sim 60 \mathrm{~nm}$. Thus, the plastic relaxation in the shell at a smaller thickness and similar Sn content indicates that larger strain energy is present in the core/shell NW during the growth using larger Ge cores. Cross-sectional EDX measurements were performed to determine the distribution of $\mathrm{Sn}$ across the shell thickness. In the case of $50 \mathrm{~nm}$ Ge cores, the GeSn shell exhibits a hexagonal shape bounded by $\{112\}$ facets and nm-thin, Sn-poor sunburst stripes along the vertices. ${ }^{15}$ On the contrary, as shown in Fig. 3, $100 \mathrm{~nm}$-core NWs have a more irregular morphology with both $\{112\}$ and $\{110\}$ facets. Also, the composition becomes inhomogeneous, with a Sn content up to $\sim 21$ at. $\%$ along the radial $\langle 112\rangle$ directions and up to $\sim 10$ at. $\%$ along the radial $\langle 110\rangle$ directions. The precise shape and composition profiles
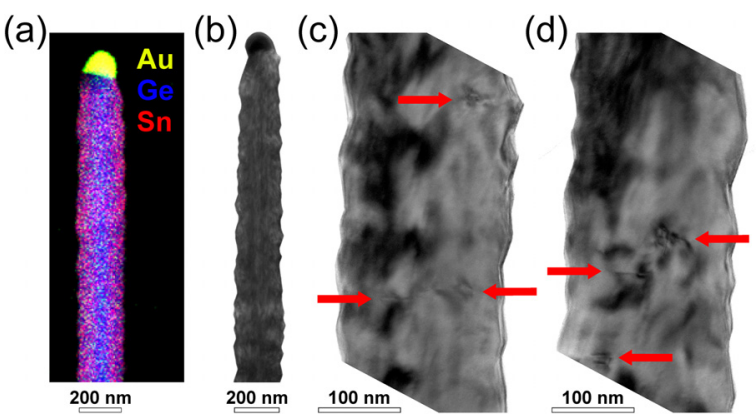

FIG. 2. (a) EDX compositional map showing the presence of the GeSn shell around the $100 \mathrm{~nm}$ Ge core. (b)-(d) Bright-field TEM images acquired along the [110] zone axis of a $\mathrm{Ge} / \mathrm{GeSn}$ core/shell NW with a $100 \mathrm{~nm}$ core. Defects are highlighted by red arrows. 
(a)
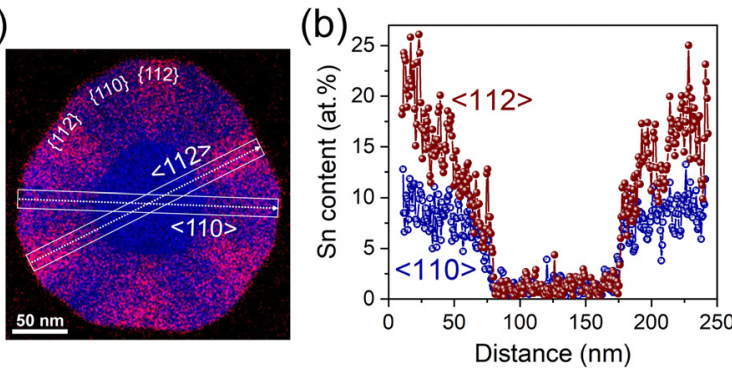

FIG. 3. (a) and (b) Cross-sectional EDX compositional map (a) and corresponding plot of the Sn content as a function of the distance along the $\langle 112\rangle$ and $\langle 110\rangle$ radial directions (b).

are found to strongly depend on the actual growth conditions, i.e., $\mathrm{SnCl}_{4}$ precursor flow. A detailed understanding of this complex behavior, mostly influenced by the $\mathrm{Sn}$ incorporation dynamics, is beyond the scope of the present letter and will be addressed in a separate work. ${ }^{32}$

We now focus on the characterization of the residual strain in the GeSn shell. A quantitative determination of the strain distribution in cross-sectional TEM samples using electron diffraction is challenging. ${ }^{16}$ Strain imaging in TEM would require both compositional mapping and lattice periodicity mapping on the nanometer scale because of the inhomogeneous $\mathrm{Sn}$ incorporation in the GeSn shell. To circumvent this problem, we use a different strategy by estimating the elastic strain relaxation in the core/shell NW system by FEM simulations. ${ }^{16}$ The NW is modeled as a dodecagonal Ge core, along the [111] direction, surrounded by the GeSn shell bounded by six main $\{112\}$ facets and six smaller $\{110\}$ ones, perpendicular to the substrate (supplementary material S4). The $\mathrm{Sn}$ composition is set differently along the $\langle 112\rangle$ and $\langle 110\rangle$ portions matching the EDX data in Fig. 3, focusing the analysis on the most critical case of high strain and high Sn content variation, where the effect of different core sizes is enhanced (a lower Sn content of 10.5 at. \% is discussed in supplementary material S4). The linear increase with the radius made evident in Fig. 3(c), promoted by compositional pulling due to strain relaxation, ${ }^{16}$ is included in the simulations. To address the role of the Ge core diameter in the strain relaxation mechanism, the experimental analysis was restricted to the growth conditions returning the more homogeneous $\mathrm{Sn}$ incorporation without introducing an additional degree of complexity, e.g., without a large change in the morphology and segregation in the GeSn shell. ${ }^{32}$ The strain in the NW originates from the (bulk) lattice mismatch between the Ge core, which is the initial template for the epitaxial growth, and the GeSn shell. ${ }^{33}$ We note that strain induced by the difference between the thermal expansion coefficients of $\mathrm{Ge}-\mathrm{GeSn}$ is negligible $(<0.1 \%)$ at a growth temperature of $320^{\circ} \mathrm{C}$ considered here. ${ }^{34}$ The NW has three main relaxation mechanisms, according to its symmetry around the axis. Radially, the shell can expand freely toward the free surface, while tangentially it is bounded by a ring geometry around the core; therefore, it remains compressed as shown by the color maps in Fig. 4(a). Along the axial direction, the relaxation of the GeSn shell requires an axial tensile deformation of the core, as it can be seen by the color maps in Figs. 4(a) and 4(b) for a $60 \mathrm{~nm}$-thick shell. Simulations have been performed to monitor the variation during growth of the strain at the surface, i.e., where the incorporation of $\mathrm{Sn}$ adatoms occurs. Different Ge core diameters are compared in (a)

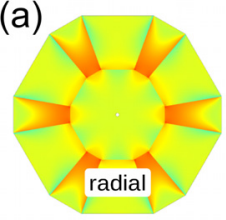

(c)

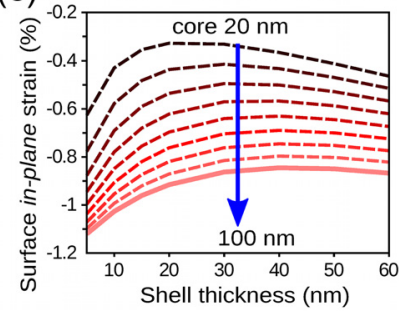

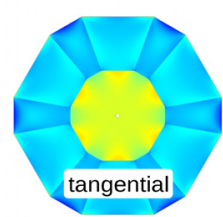

(d)
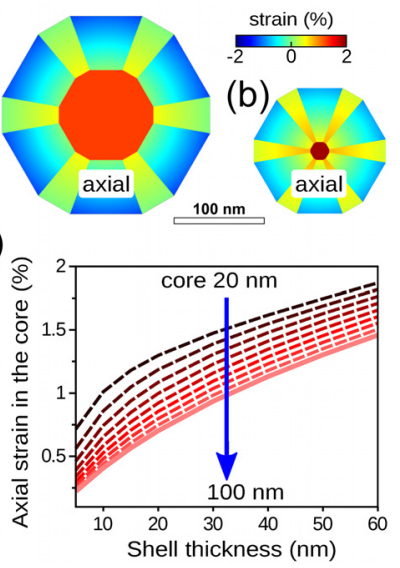

FIG. 4. (a) Color map of the radial, tangential, and axial FEM strain components for a $100 \mathrm{~nm}$ core diameter and a $60 \mathrm{~nm}$-thick shell. (b) Axial strain for a $20 / 60 \mathrm{~nm} \mathrm{Ge} /$ GeSn core/shell NW heterostructure. (c) and (d) In-plane strain (average of tangential and axial) at the shell surface (c) and axial strain in the Ge core (d) as a function of the shell thickness, for different core diameters (10 nm increment). A linear composition gradient along the $\langle 112\rangle$ direction from 9 at. $\%$ up to 18 at. $\% \mathrm{Sn}$ for a $60 \mathrm{~nm}$-thick shell (7 at. \% to 10 at. \% Sn along the $\langle 110\rangle$ direction) is assumed to match the experiments. Solid lines correspond to the NW of Fig. 3.

Fig. 4(c), assuming the same Sn distribution for consistency. In the initial stages of deposition, the shell grows pseudomorphically relaxing only through a slight expansion toward the lateral free surfaces. When the shell becomes thicker, the elastic budget is large enough to induce the deformation of the core along the axial direction, resulting in a large decrease in the residual strain. This strain partitioning mechanism is less effective for the largest cores. Indeed, a large increase in the in-plane compressive strain from $-0.3 \%$ to $-0.9 \%$ is predicted when changing the Ge core diameter from $20 \mathrm{~nm}$ to $100 \mathrm{~nm}$ at a constant GeSn shell thickness of $20 \mathrm{~nm}$. Thus, an increase in the overall strain energy in the core/shell system with the increasing Ge core diameter is present, which is also maintained at larger shell thicknesses. The enhanced relaxation provided by the lattice expansion along the NW axis allows the accommodation of more Sn, resulting in an increased incorporation of $\mathrm{Sn}$ as the shell grows larger. ${ }^{16}$ Since the Sn composition is not uniform, the evaluation of the residual strain is not simply related to the relative volume of the core and the shell. Therefore, FEM simulations are strictly required for a precise estimation of the NW deformation. The inner part of the shell, having a lower Sn composition, may exhibit even a tensile strain, behaving, in the same way as the Ge core, as a compliant substrate for the outer shell which has a larger volume and a stronger tendency to expand, because of the higher Sn content. This is particularly evident in the color map in Fig. 4(b) for the NW with the smallest Ge core $(20 \mathrm{~nm})$, which can be easily deformed by the surrounding GeSn shell. The computed axial strain averaged in the core volume is plotted in Fig. 4(d) as a function of the GeSn shell thickness, for different core diameters. The axial expansion is more than $3 \times$ times larger than the radial and tangential ones, revealing a substantially uniaxial character for the core deformation. It is worth noting that our calculations provide the maximum residual strain within the NW, since purely elastic relaxation is taken into account. However, in the case of larger cores, 
the strain accumulation in the shell is likely to exceed the onset of plastic relaxation, with the development of extended defects, partially relieving strain [Figs. 2(c)-2(d)]. In addition, the critical thickness should be larger than in (not compliant) planar substrates; still, the circular periodicity induced by the tubular configuration of the shell is likely to affect the nucleation and multiplication mechanisms of misfit dislocations. $^{35}$ This issue would require a detailed HRTEM analysis, not presently viable, as explained above. Finally, we note that a tensile axial strain above $2 \%$ in the $20 \mathrm{~nm}$ Ge core can be achieved at a $\mathrm{GeSn}$ shell thickness larger than $60 \mathrm{~nm}$ [Fig. 4(d)], which could eventually induce an indirect to direct bandgap transition in the Ge core, thus enriching the physical properties of a fully integrated group-IV semiconductor optoelectronic platform. ${ }^{36-38}$

In conclusion, the growth of GeSn alloys in a Ge/GeSn core/shell NW heterostructure shows few striking differences with respect to conventional planar growth. In the latter, the uniform plastic relaxation allows for enhanced Sn incorporation beyond the dislocated region while keeping a limited surface roughness $(<10 \mathrm{~nm}))^{8,11,14,19}$ When using $\mathrm{Ge} / \mathrm{GeSn}$ core/shell NWs, competing strain relaxation between the (fewer) more geometrically constrained defects and the nonuniform Sn distribution (on the $\{110\}-\{112\}$ facets) takes place. Therefore, the growth of GeSn alloys in a core/shell NW geometry is beneficial when the strain in the shell is kept below the threshold for plastic relaxation and hence when using thinner $(50 \mathrm{~nm}) \mathrm{Ge}$ cores. On the contrary, for larger $(100 \mathrm{~nm}) \mathrm{Ge}$ cores, the higher strain in the shell induces a more irregular growth of the GeSn shell, affected by both structural imperfections (multifaceted and rotated sidewalls and defects) and compositional inhomogeneities. These results show the critical role of strain in the growth of GeSn alloys, which can be further investigated with the development of SiGeSn alloys for enhanced strain and bandgap engineering. ${ }^{9}$

See the supplementary material for additional information on the growth conditions, structural characterization, and FEM simulations.

The authors thank P. J. van Veldhoven for the technical support with the MOVPE reactor. This work was supported by the Dutch Organization for Scientific Research (No. NWO-VICI 700.10.441) and by the Dutch Technology Foundation (No. STW 12744) and Philips Research. Solliance and the Dutch province of Noord-Brabant are acknowledged for funding the TEM facility.

The authors declare no competing financial interest.

\section{REFERENCES}

${ }^{1}$ R. M. France, F. Dimroth, T. J. Grassman, and R. R. King, MRS Bull. 41, 202 (2016). ${ }^{2}$ S. B. Samavedam and E. A. Fitzgerald, J. Appl. Phys. 81, 3108 (1997).

${ }^{3}$ M. T. Currie, S. B. Samavedam, T. A. Langdo, C. W. Leitz, and E. A. Fitzgerald, Appl. Phys. Lett. 72, 1718 (1998)

${ }^{4}$ D. D. Cannon, J. Liu, D. T. Danielson, S. Jongthammanurak, U. U. Enuha, K. Wada, J. Michel, and L. C. Kimerling, Appl. Phys. Lett. 91, 252111 (2007).

${ }^{5}$ S. Wirths, R. Geiger, N. von den Driesch, G. Mussler, T. Stoica, S. Mantl, Z. Ikonic, M. Luysberg, S. Chiussi, J. M. Hartmann, H. Sigg, J. Faist, D. Buca, and D. Grützmacher, Nat. Photonics 9, 88 (2015).

${ }^{6}$ J. Margetis, S. Al-Kabi, W. Du, W. Dou, Y. Zhou, T. Pham, P. Grant, S. Ghetmiri, A. Mosleh, B. Li, J. Liu, G. Sun, R. Soref, J. Tolle, M. Mortazavi, and S.-Q. Yu, ACS Photonics 5, 827 (2018)

${ }^{7}$ V. Reboud, A. Gassenq, N. Pauc, J. Aubin, L. Milord, Q. M. Thai, M. Bertrand, K. Guilloy, D. Rouchon, J. Rothman, T. Zabel, F. Armand Pilon, H. Sigg, A. Chelnokov, J. M. Hartmann, and V. Calvo, Appl. Phys. Lett. 111, 092101 (2017).
${ }^{8}$ S. Assali, J. Nicolas, S. Mukherjee, A. Dijkstra, and O. Moutanabbir, Appl. Phys. Lett. 112, 251903 (2018).

${ }^{9}$ A. Attiaoui, S. Wirth, A.-P. Blanchard-Dionne, M. Meunier, J. M. Hartmann, D. Buca, and O. Moutanabbir, J. Appl. Phys. 123, 223102 (2018).

${ }^{10}$ J. Margetis, S.-Q. Yu, N. Bhargava, B. Li, W. Du, and J. Tolle, Semicond. Sci. Technol. 32, 124006 (2017).

${ }^{11}$ S. Assali, J. Nicolas, and O. Moutanabbir, J. Appl. Phys. 125, 025304 (2019).

${ }^{12}$ J. M. Hartmann, A. Abbadie, J. P. Barnes, J. M. Fédéli, T. Billon, and L. Vivien, J. Cryst. Growth 312, 532 (2010).

${ }^{13}$ Y. Yamamoto, P. Zaumseil, T. Arguirov, M. Kittler, and B. Tillack, Solid. State. Electron. 60, 2 (2011).

${ }^{14}$ W. Dou, M. Benamara, A. Mosleh, J. Margetis, P. Grant, Y. Zhou, S. Al-Kabi, W. Du, J. Tolle, B. Li, M. Mortazavi, and S.-Q. Yu, Sci. Rep. 8, 5640 (2018).

${ }^{15}$ S. Assali, A. Dijkstra, A. Li, S. Koelling, M. A. Verheijen, L. Gagliano, N. von den Driesch, D. Buca, P. M. Koenraad, J. E. M. Haverkort, and E. P. A. M. Bakkers, Nano Lett. 17, 1538 (2017).

${ }^{16}$ M. Albani, S. Assali, M. A. Verheijen, S. Koelling, R. Bergamaschini, F. Pezzoli, E. P. A. M. Bakkers, and L. Miglio, Nanoscale 10, 7250 (2018).

${ }^{17}$ J. Aubin, J. M. Hartmann, A. Gassenq, L. Milord, N. Pauc, V. Reboud, and V. Calvo, J. Cryst. Growth 473, 20 (2017).

${ }^{18}$ D. Weisshaupt, P. Jahandar, G. Colston, P. Allred, J. Schulze, and M. Myronov, in 40th International Convection on Information and Communication Technology, Electronics and Microelectronics (IEEE, 2017), pp. 43-47.

${ }^{19}$ J. Aubin, J. M. Hartmann, A. Gassenq, J. L. Rouviere, E. Robin, V. Delaye, D. Cooper, N. Mollard, V. Reboud, and V. Calvo, Semicond. Sci. Technol, 32, 094006 (2017).

${ }^{20}$ J. Aubin, J. M. Hartmann, J. P. Barnes, J. B. Pin, and M. Bauer, ECS Trans. 75, 387 (2016).

${ }^{21}$ É. Bouthillier, S. Assali, J. Nicolas, and O. Moutanabbir, preprint arXiv:1901.00436 (2019).

${ }^{22}$ J. Aubin and J. M. Hartmann, J. Cryst. Growth 482, 30 (2018).

${ }^{23}$ W. Wang, Q. Zhou, Y. Dong, E. S. Tok, and Y.-C. Yeo, Appl. Phys. Lett. 106, 232106 (2015)

${ }^{24}$ S. Biswas, J. Doherty, D. Saladukha, Q. Ramasse, D. Majumdar, M. Upmanyu, A. Singha, T. Ochalski, M. A. Morris, and J. D. Holmes, Nat. Commun. 7, 11405 (2016).

${ }^{25}$ M. S. Seifner, S. Hernandez, J. Bernardi, A. Romano-Rodriguez, and S. Barth, Chem. Mater. 29, 9802 (2017).

${ }^{26}$ L. Gagliano, M. Albani, M. A. Verheijen, E. P. A. M. Bakkers, and L. Miglio, Nanotechnology 29, 315703 (2018).

${ }^{27}$ L. Gagliano, A. Belabbes, M. Albani, S. Assali, M. A. Verheijen, L. Miglio, F. Bechstedt, J. E. M. Haverkort, and E. P. A. M. Bakkers, Nano Lett. 16, 7930 (2016).

${ }^{28}$ A. C. Meng, C. S. Fenrich, M. R. Braun, J. P. McVittie, A. F. Marshall, J. S. Harris, and P. C. McIntyre, Nano Lett. 16(12), 7521-7529 (2016).

${ }^{29}$ A. C. Meng, M. R. Braun, Y. Wang, C. S. Fenrich, M. Xue, D. R. Diercks, B. P. Gorman, M.-I. Richard, A. F. Marshall, W. Cai, J. S. Harris, and P. C. McIntyre, Mater. Today Nano 5, 100026 (2019).

${ }^{30}$ H. Wang, M. Upmanyu, and C. V. Ciobanu, Nano Lett. 8, 4305 (2008).

${ }^{31}$ V. Schmidt, P. C. McIntyre, and U. Gösele, Phys. Rev. B 77, 235302 (2008).

${ }^{32}$ S. Assali, R. Bergamaschini, E. Scalise, M. A. Verheijen, M. Albani, A. Li, S. Koelling, E. P. A. M. Bakkers, F. Montalenti, and L. Miglio, preprint arXiv:1906.11694 (2019).

${ }^{33}$ F. Gencarelli, B. Vincent, J. Demeulemeester, A. Vantomme, A. Moussa, A. Franquet, A. Kumar, H. Bender, J. Meersschaut, W. Vandervorst, R. Loo, M Caymax, K. Temst, and M. Heyns, ECS J. Solid State Sci. Technol. 2, P134 (2013).

${ }^{34}$ Group IV Elements, IV-IV and III-V Compounds. Part B-Electronic, Transport, Optical and Other Properties, edited by O. Madelung, U. Rössler, and M. Schulz (Springer-Verlag, Berlin/Heidelberg, 2002).

${ }^{35}$ Y. Liang, W. D. Nix, P. B. Griffin, and J. D. Plummer, J. Appl. Phys. 97, 043519 (2005).

${ }^{36}$ M. J. Süess, R. Geiger, R. a Minamisawa, G. Schiefler, J. Frigerio, D. Chrastina, G. Isella, R. Spolenak, J. Faist, and H. Sigg, Nat. Photonics 7, 466 (2013).

${ }^{37}$ J. Petykiewicz, D. Nam, D. S. Sukhdeo, S. Gupta, S. Buckley, A. Y. Piggott, J. Vučković, and K. C. Saraswat, Nano Lett. 16, 2168 (2016).

${ }^{38}$ K. Guilloy, N. Pauc, A. Gassenq, Y.-M. Niquet, J.-M. Escalante, I. Duchemin, S. Tardif, G. Osvaldo Dias, D. Rouchon, J. Widiez, J.-M. Hartmann, R. Geiger, T. Zabel, H. Sigg, J. Faist, A. Chelnokov, V. Reboud, and V. Calvo, ACS Photonics 3, 1907 (2016) 